\title{
Prevalência de cárie e sua correlação com a classificação clínica e imunológica em crianças infectadas pelo HIV
}

\section{Prevalence of caries and its correlation with clinical and immunological classification in HIV-infected children}

\author{
Gloria Fernanda CASTRO* \\ Ivete Pomarico Ribeiro de SOUZA** \\ Ricardo Hugo Silva e OLIVEIRA*** \\ Maristela Barbosa PORTELA**** \\ Cristiane ESTEVES****
}

\begin{abstract}
CASTRO, G. F.; SOUZA, I. P. R. de; OLIVEIRA, R. H. S. e; PORTELA, M. B.; ESTEVES, C. Prevalência de cárie e sua correlação com a classificação clínica e imunológica em crianças infectadas pelo HIV. Pesqui Odontol Bras, v. 15, n. 2, p. 91-97, abr./jun. 2001.
\end{abstract}

\begin{abstract}
Este estudo tem como objetivo determinar a experiência de cárie em crianças infectadas pelo HIV, correlacionada com a classificação clínica e imunológica $\left(\mathrm{CDC}^{3}, 1994\right)$. Participaram da pesquisa 92 crianças (50 meninas e 42 meninos), com média de idade de 5,77 $\pm 3,31$ anos (6 meses a 13 anos), com diagnóstico definitivo para o HIV, todos pacientes com atendimento ambulatorial. Foi realizado exame bucal para determinar os índices ceo/CPOD e os dados de história médica foram coletados dos prontuários médicos. Na dentição decídua de crianças mais jovens (até 5 anos), apesar de a prevalência de cárie ter apresentado valores maiores naquelas mais comprometidas clínica e imunologicamente, não houve diferença estatisticamente significante entre as diversas categorias de classificação. Nas crianças de maior idade, isto também foi observado, apesar de terem sido encontrados valores de CPOD maiores nas crianças mais doentes.
\end{abstract}

UNITERMOS: Infecções por HIV; Cárie dentária; Criança.

\section{INTRODUÇÃO}

Estudos demonstram que crianças infectadas pelo HIV tendem a ter maior experiência de cárie do que as saudáveis ${ }^{1,10,12,17,18,19}$. Este parece ser um grande problema causado, na maioria das vezes, por negligência dos responsáveis em relação à higiene bucal e pelo elevado teor de sacarose contido nos inúmeros medicamentos pediátricos ${ }^{8,9,11}$.

Em 1991, GEHRKER; JOHNSEN ${ }^{6}$ relataram o primeiro caso de cárie de mamadeira associado a terapia anti-HIV, em que uma criança de dois anos fazia uso de Retrovir ${ }^{\circledR}$ associado a mamadeira noturna e má higiene oral. Segundo HOWELL et al. ${ }^{10}$ (1992), a prevalência de cárie em crianças infectadas pelo HIV é muito alta, principalmente naquelas com dentição decídua. TOFSKY et al. ${ }^{19}$ (1995) encontraram um ceo(s) médio de 8,3 para crianças com HIV, enquanto para as crianças não infecta- das pelo HIV esta média foi 3,1, o que demonstra, segundo os autores, a necessidade de orientação e tratamento para esses pacientes infectados.

Um estudo comparativo de prevalência de cárie, realizado por SOUZA et al. ${ }^{17}$ (1996) em crianças infectadas pelo HIV e crianças sem evidência de imunossupressão, mostrou diferença estatisticamente significante entre as médias de ceo $(5,29 \times 2,59)$ e CPOD $(2,36 \times 0,74)$ dos dois grupos, respectivamente. Em um estudo posterior, SOUZA et al. ${ }^{16}$ (1996), ainda com essas crianças, analisaram e compararam alguns fatores de risco para cárie, tais como nivel de higiene oral e exposição a fluoretos. Observaram que as diferenças entre os grupos foram pequenas, levando a suspeitar que a alta prevalência de cárie em crianças infectadas pelo HIV pudesse estar relacionada à situação de imunossupressão desses pacientes.

*Doutoranda; **Professora Titular de Odontopediatria; ***Médico Chefe do Ambulatório de AIDS Pediátrica do Instituto de

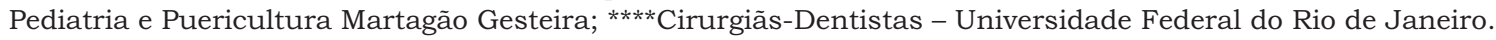


CASTRO, G. F.; SOUZA, I. P. R. de; OLIVEIRA, R. H. S. e; PORTELA, M. B.; ESTEVES, C. Prevalência de cárie e sua correlação com a classificação clínica e imunológica em crianças infectadas pelo HIV. Pesqui Odontol Bras, v. 15, n. 2, p. 91-97, abr./jun. 2001.

MADIGAN et al. ${ }^{12}$ (1996), em um estudo do tipo caso-controle com 147 crianças, observaram que o ceo médio das infectadas $(3,8)$ era bem maior que a média de seus irmãos soronegativos $(1,5)$. Além disso, as crianças infectadas pelo HIV tinham um número estatisticamente maior de UFC de estreptococos do grupo mutans e de lactobacilos, quando comparadas com as outras. Outros estudos recentes demonstram que a alta prevalência de cárie em crianças infectadas parece ser maior naquelas em fase mais avançada da doença e com grau de imunodepressão mais severo ${ }^{1,12}$.

Sendo assim, o objetivo deste estudo é: 1- determinar a prevalência de cárie em crianças infectadas pelo HIV; 2- correlacionar a prevalência de cárie com a classificação clínica e imunológica.

\section{MATERIAL E MÉTODOS}

\section{População}

Noventa e duas crianças, entre 6 meses e 13 anos de idade, com diagnóstico definitivo para o HIV (CDC ${ }^{3}$, 1994), pacientes do Ambulatório de AIDS Pediátrica do Instituto de Puericultura e Pediatria Martagão Gesteira (IPPMG), Rio de Janeiro, $\mathrm{RJ}$, foram examinadas pelo Projeto AIDS em Odontopediatria (Departamento de Odontopediatria Universidade Federal do Rio de Janeiro), no período de março de 97 a março de 98.

\section{Coleta de dados}

Foi feita uma coleta dos dados de identificação, história médica e exame bucal contidos nas fichas clínicas do Projeto. A história médica consistia na classificação clínica e imunológica (Quadros 1 e 2), no uso de medicamentos anti-retrovirais e percentual de CD4, coletados dos prontuários médicos pelo examinador. O valor de CD4 (parâmetro imunológico para determinar valores de linfócitos T4) utilizado era o mais próximo da data do exame bucal (intervalo máximo de 3 meses).

Inicialmente, era realizado o IHO-S preconizado por GREENE; VERMILLION ${ }^{7}$ (1964) e escovação supervisionada; logo após, era feito o exame bucal com a criança deitada em uma maca e o examinador (GFC), de pé, contava com o auxílio de espelho bucal plano, sonda exploradora de ponta romba, gaze e uma pequena lanterna para ajudar na iluminação para a obtenção dos índices ceo/CPOD $\left(\mathrm{OMS}^{22}, 1987\right)$.

\section{Aspectos éticos}

Todos os pacientes tinham ficha de consentimento livre e esclarecido, assinado pelo responsável e o Projeto tem aprovação do Comitê de Ética em Pesquisa de Núcleo de Saúde Coletiva (NESC/ UFRJ).

As crianças do ambulatório recebem atendimento por meio do Programa de Promoção de Saú-

QUADRO 1 - Classificação clínica e imunológica de AIDS pediátrica (CDC³, 1994).

\begin{tabular}{|l|c|c|c|c||}
\hline Categorias clínicas & $\begin{array}{c}\mathrm{N} \\
\text { Imunossupressão }\end{array}$ & $\begin{array}{c}\mathrm{A} \\
\text { (sintomas leves) }\end{array}$ & $\begin{array}{c}\mathrm{B} \\
\text { (sintomas moderados) }\end{array}$ & $\begin{array}{c}\mathrm{C} \\
\text { (sintomas graves) }\end{array}$ \\
\hline 1 (ausente) & $\mathrm{N} 1$ & $\mathrm{~A} 1$ & $\mathrm{~B} 1$ & $\mathrm{C} 1$ \\
\hline 2 (moderada) & $\mathrm{N} 2$ & $\mathrm{~A} 2$ & $\mathrm{~B} 2$ & $\mathrm{C} 2$ \\
\hline 3 (grave) & $\mathrm{N} 3$ & $\mathrm{~A} 3$ & $\mathrm{~B} 3$ & $\mathrm{C} 3$ \\
\hline
\end{tabular}

Fonte: 1994 Revised classification system for human immunodeficiency virus infection in children less than 13 years of age $(\mathrm{CDC})^{3}$.

QUADRO 2 - Classificação imunológica de AIDS pediátrica (CDC³, 1994) segundo a idade.

\begin{tabular}{|c|c|c|c|c|c|c|}
\hline \multirow[t]{3}{*}{ Idade } & \multicolumn{2}{|c|}{$<12$ meses } & \multicolumn{2}{|c|}{$1-5$ anos } & \multicolumn{2}{|c|}{ 6-12 anos } \\
\hline & \multicolumn{2}{|c|}{ CD4 } & \multicolumn{2}{|c|}{ CD4 } & \multicolumn{2}{|c|}{ CD4 } \\
\hline & Total & $\%$ & Total & $\%$ & Total & $\%$ \\
\hline 1 (ausente) & $\geq 1.500$ & $\geq 25$ & $\geq 1.000$ & $\geq 25$ & $\geq 500$ & $\geq 25$ \\
\hline 2 (moderada) & $750-1.499$ & $15-24$ & $500-999$ & $15-24$ & $200-499$ & $15-24$ \\
\hline 3 (grave) & $<750$ & $<15$ & $<500$ & $<15$ & $<200$ & $<15$ \\
\hline
\end{tabular}

Fonte: 1994 Revised classification system for human immunodeficiency virus infection in children less than 13 years of age $(\mathrm{CDC})^{3}$. 
CASTRO, G. F.; SOUZA, I. P. R. de; OLIVEIRA, R. H. S. e; PORTELA, M. B.; ESTEVES, C. Prevalência de cárie e sua correlação com a classificação clínica e imunológica em crianças infectadas pelo HIV. Pesqui Odontol Bras, v. 15, n. 2, p. 91-97, abr./jun. 2001.

de Bucal que consiste na realização de escovação supervisionada, reforço das instruções de higiene bucal e dieta e aplicação de fluoretos na escova em todas as vezes que o paciente comparece à consulta com o médico, o que se dá uma vez por mês. A cada três meses, um novo exame bucal era realizado. Quando a criança apresentava cavidades por lesão de cárie, eram feitas restaurações pela técnica de restauração atraumática (ART) descrita por FRENCKEN ${ }^{5}$ (1996). Quando necessário, eram realizadas exodontias.

\section{Análises estatísticas}

O teste de Kruskal-Wallis foi utilizado para comparar os índices de cárie de acordo com a classificação clínica e imunológica. Em relação à variável idade, foi utilizado o Teste de Mann-Whitney, enquanto o Qui-quadrado mostrou a relação entre percentual de crianças isentas de cárie e classificação clínica.

\section{RESULTADOS}

As médias de ceo e CPOD encontradas podem ser vistas na Tabela 1 . A prevalência de cárie na dentição decídua foi maior nas crianças com mais idade, sendo a diferença estatisticamente significante $(\mathrm{p}<0,01)$.

$\mathrm{Na}$ faixa etária de até 5 anos de idade, todos apresentavam dentição decídua e as correlações entre prevalência de cárie neste grupo e a classificação clínica e imunológica podem ser vistas nas Tabelas 2 e 3.

Apesar de observado que as crianças com sintomas moderados (B) e/ou graves (C) tiveram valores de ceo mais elevados que as com sintomas leves (A) e/ou ausentes (N), não houve diferença estatisticamente significativa entre a prevalência de cárie quando consideradas as quatro categorias de classificação clínica. Em relação à classificação imunológica, também não houve diferença entre as médias de ceo, embora aquelas com imunossupressão grave (classificação 3) tenham apresentado ceo mais alto do que as menos comprometidas imunologicamente. Nesta faixa etária, 22 (46,8\%) crianças estavam livres de cárie (sem lesão de cárie) e o percentual de crianças livres de cárie em cada categoria pode ser visto no Gráfico 1.

Das 47 crianças deste grupo etário, 31 usavam algum tipo de medicamento anti-retroviral, sendo o ceo destas $4,07 \pm 5,48$. Das 16 que não usavam nenhuma droga, a média de ceo foi $2,00 \pm 2,53$.

TABELA 1 - Distribuição das crianças infectadas pelo HIV de acordo com a faixa etária e os índices de cárie (ceo/CPOD) ( $\mathrm{n}=92)$ (Rio de Janeiro, 1998).

\begin{tabular}{l|c|c|c|c|c|c}
\hline \hline \multirow{2}{*}{ Faixa etária } & \multirow{2}{*}{$\mathrm{n}(\%)$} & \multirow{2}{*}{$\begin{array}{c}\text { Idade } \\
\text { média } \pm \text { d.p. }\end{array}$} & \multicolumn{2}{|c|}{ ceo } & \multicolumn{2}{c}{ CPOD } \\
\cline { 4 - 7 } & & & Média \pm d.p. ${ }^{*}$ & $\mathrm{n}$ & Média \pm d.p. & $\mathrm{n}$ \\
\hline Até 5 anos & $47(51,1)$ & $3,23 \pm 1,32$ & $3,36 \pm 4,76$ & 47 & - & - \\
\hline+ de 5 anos & $45(49,9)$ & $8,42 \pm 2,61$ & $5,70 \pm 4,06$ & 40 & $2,06 \pm 1,92$ & 34 \\
\hline Total & $92(100)$ & $5,77 \pm 3,31$ & $4,44 \pm 4,58$ & 87 & $2,06 \pm 1,92$ & 34 \\
\hline \hline
\end{tabular}

${ }^{*} \mathrm{p}=0,0006$ (estatisticamente significante - teste de Mann-Whitney).

TABELA 2 - Correlação entre prevalência de cárie (ceo) e classificação clínica em crianças infectadas pelo HIV com até 5 anos de idade ( $\mathrm{n}=47$ ) (Rio de Janeiro, 1998).

\begin{tabular}{c|c|c}
\hline \hline \multirow{2}{*}{$\begin{array}{c}\text { Classificação } \\
\text { clínica }\end{array}$} & \multicolumn{2}{|c}{ Prevalência de cárie } \\
\cline { 2 - 3 } & Média \pm d.p. & $\mathrm{n}$ \\
\hline $\mathrm{N}$ & $0,50 \pm 1,0$ & 4 \\
\hline $\mathrm{A}$ & $1,60 \pm 2,31$ & 10 \\
\hline $\mathrm{B}$ & $5,08 \pm 5,93$ & 12 \\
\hline $\mathrm{C}$ & $3,76 \pm 5,01$ & 21 \\
\hline \hline
\end{tabular}

$\mathrm{p}=0,33$ (Kruskal-Wallis). $\mathrm{N}=$ sintomas ausentes; $\mathrm{A}=$ sintomas leves; $\mathrm{B}=$ sintomas moderados; $\mathrm{C}=$ sintomas graves.
TABELA 3 - Correlação entre prevalência de cárie (ceo) e classificação imunológica em crianças infectadas pelo HIV com até 5 anos de idade $(n=47)$ (Rio de Janeiro, 1998).

\begin{tabular}{c|c|c}
\hline \hline \multirow{2}{*}{ Imunossupressão } & \multicolumn{2}{|c}{ Prevalência de cárie } \\
\cline { 2 - 3 } & Média \pm d.p. & $\mathrm{n}$ \\
\hline 1 & $3,60 \pm 4,99$ & 10 \\
\hline 2 & $2,75 \pm 4,01$ & 20 \\
\hline 3 & $3,94 \pm 5,58$ & 17 \\
\hline \hline
\end{tabular}

$\mathrm{p}=0,69$ (Kruskal-Wallis). 1 = ausente; $2=$ moderada; $3=$ grave. 
CASTRO, G. F.; SOUZA, I. P. R. de; OLIVEIRA, R. H. S. e; PORTELA, M. B.; ESTEVES, C. Prevalência de cárie e sua correlação com a classificação clínica e imunológica em crianças infectadas pelo HIV. Pesqui Odontol Bras, v. 15, n. 2, p. 91-97, abr./jun. 2001.

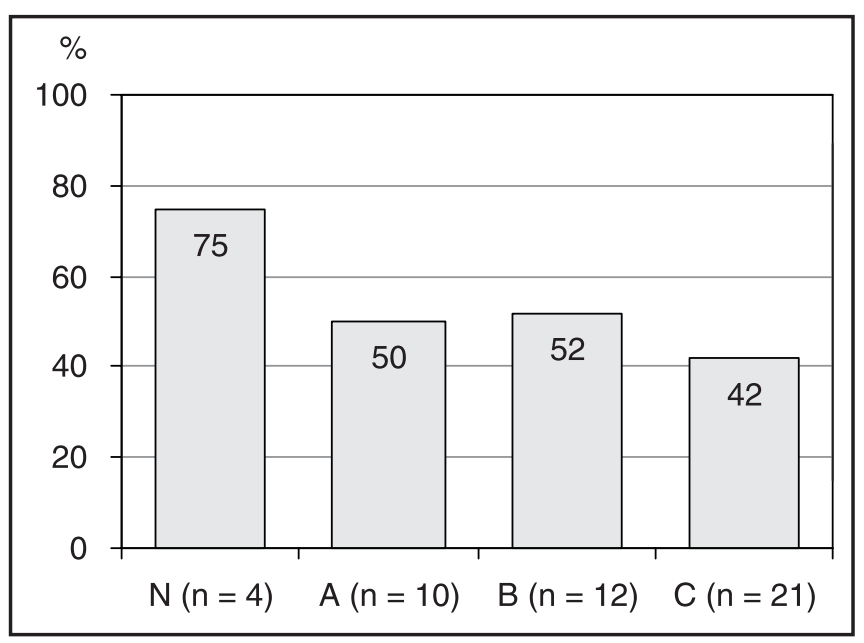

GRÁFICO 1 - Correlação entre percentual de crianças livres de cárie infectadas pelo HIV e classificação clínica ( $\mathrm{n}=47$ ). Obs.: $\mathrm{p}>0,05$ (não significativo - teste de $\chi^{2}$ ). $\mathrm{N}=$ sintomas ausentes; $\mathrm{A}=$ sintomas leves; $\mathrm{B}=$ sintomas moderados; $\mathrm{C}=$ sintomas graves.

Apesar de ter sido uma prevalência de cárie $50 \%$ menor para aquelas que não usavam medicamento, não houve diferença estatística entre os grupos $(\mathrm{p}=0,43)$. A média de idade foi similar nos dois grupos $(3,35 \pm 1,25$ e 3,0 $\pm 1,47$, respectivamente) $(\mathrm{p}=0,36)$.

Para as crianças com mais de cinco anos, as correlações com as classificações clínica e imunológica encontram-se nas Tabelas 4 e 5 . A prevalência de cárie em dentição decídua deste grupo foi alta independentemente da classificação clínica e, em relação aos valores de CPOD, estes apresentaram-se maiores para as crianças com sintomas mais graves da infecção pelo HIV (classificação C), embora não tenha havido diferença estatisticamente significativa. Quanto à classificação imunológica, tanto para dentição decídua (ceo) como para permanente (CPOD), observa-se que à medida que o grau de imunossupressão fica mais severo, maiores as médias dos índices encontrados, entretanto não foram observadas diferenças estatisticamente significantes entre as categorias de classificação. Nesta faixa etária, nenhuma criança era livre de cárie.

Quando observado neste grupo se existia correlação entre uso de medicamento anti-retroviral e prevalência de cárie, constatou-se que na dentição decídua os valores de ceo foram semelhantes $(5,70 \pm 4,10 \times 5,7 \pm 4,15)$. Já na dentição permanente, a experiência de cárie foi quase $100 \%$ maior nas crianças que faziam uso de alguma droga
TABELA 4 - Correlação entre prevalência de cárie (ceo/CPOD) e classificação clínica das crianças infectadas pelo HIV com mais de 5 anos de idade $(n=45)$.

\begin{tabular}{|c|c|c|c|c|}
\hline \multirow{3}{*}{$\begin{array}{c}\text { Classificação } \\
\text { clínica }\end{array}$} & \multicolumn{4}{|c|}{ Prevalência de cárie } \\
\hline & \multicolumn{2}{|l|}{ ceo* } & \multicolumn{2}{|l|}{ CPOD** } \\
\hline & Média \pm d.p. & $\mathrm{n}$ & Média \pm d.p. & $\mathrm{n}$ \\
\hline $\mathrm{N}$ & $5,00 \pm 2,83$ & 2 & $1,50 \pm 2,12$ & 2 \\
\hline A & $6,00 \pm 4,70$ & 15 & $1,00 \pm 0,82$ & 4 \\
\hline $\mathrm{B}$ & $5,43 \pm 4,82$ & 14 & $2,00 \pm 2,55$ & 12 \\
\hline $\mathrm{C}$ & $5,90 \pm 3,67$ & 19 & $2,47 \pm 1,46$ & 15 \\
\hline
\end{tabular}

${ }^{*} \mathrm{p}=0,93$ (não significante - teste de Kruskal-Wallis); ${ }^{* *} \mathrm{p}=0,29$ (não significante - teste de Kruskal-Wallis). $\mathrm{N}=$ sintomas ausentes; $\mathrm{A}=$ sintomas leves; $\mathrm{B}=$ sintomas moderados; $\mathrm{C}=$ sintomas graves.

TABELA 5 - Correlação entre prevalência de cárie (ceo/CPOD) e classificação imunológica das crianças infectadas pelo HIV com mais de 5 anos de idade $(n=45)$.

\begin{tabular}{c|c|c|c|c}
\hline \hline \multirow{2}{*}{ Imunossupressão } & \multicolumn{4}{|c}{ Prevalência de cárie } \\
\cline { 2 - 5 } & \multicolumn{2}{|c}{ ceo* } & \multicolumn{2}{c}{ CPOD** } \\
\cline { 2 - 5 } & Média \pm d.p. & $\mathrm{n}$ & Média \pm d.p. & $\mathrm{n}$ \\
\hline 1 & $4,00 \pm 3,24$ & 5 & $1,20 \pm 1,10$ & 5 \\
\hline 2 & $4,61 \pm 3,62$ & 13 & $1,75 \pm 1,49$ & 12 \\
\hline 3 & $6,73 \pm 4,31$ & 22 & $2,53 \pm 2,29$ & 17 \\
\hline \hline
\end{tabular}

${ }^{*} \mathrm{p}=0,22$ (não significante - teste de Kruskal-Wallis); ${ }^{* *} \mathrm{p}=0,37$ (não significante - teste de Kruskal-Wallis). 1 = ausente; 2 = moderada; 3 = grave .

$(2,26 \pm 1,97 \times 1,23 \pm 1,60)$, embora não estatisticamente significante $(\mathrm{p}=0,19)$.

\section{DISCUSSÃO}

A prevalência de cárie dentária em crianças infectadas pelo HIV parece ser maior que nas crianças sem evidência de nenhuma doença ${ }^{2,12,16,18,19,20}$, o que mostra que esta população minoritária apresenta grande necessidade de tratamento, assim como programas de prevenção da cárie são essenciais para seu controle ${ }^{18,19}$. A prevalência de cárie encontrada neste estudo para dentição decídua (ceo) foi 4,44 e para dentição permanente (CPOD) 2,06 . SOUZA et al. ${ }^{17}$ (1996), em um estudo casocontrole, trabalhando com os pacientes do IPPMG em 1995 (crianças HIV+ e HIV-), observaram que a prevalência de cárie, naquela época, foi de 5,29 para ceo e 2,36 para CPOD nas crianças infecta- 
CASTRO, G. F.; SOUZA, I. P. R. de; OLIVEIRA, R. H. S. e; PORTELA, M. B.; ESTEVES, C. Prevalência de cárie e sua correlação com a classificação clínica e imunológica em crianças infectadas pelo HIV. Pesqui Odontol Bras, v. 15, n. 2, p. 91-97, abr./jun. 2001.

das, enquanto nas não infectadas esses valores foram de 2,59 e 0,74 , respectivamente, sendo a diferença estatisticamente significante.

CASTRO et al. ${ }^{2}$ (1996), nessa mesma época, analisaram estes pacientes em subgrupos e os resultados mostraram que o número de crianças com alto risco de cárie era 55\% maior nas crianças infectadas pelo HIV, quando comparadas com as outras. Nota-se que os valores encontrados por SOUZA et al. ${ }^{17}$ (1996) para as crianças infectadas pelo HIV são maiores que os observados neste estudo, enquanto as idades são similares $(5,3$ e 5,7 anos, respectivamente). Talvez esteja ocorrendo uma diminuição do índice de cárie dessas crianças, graças aos programas de prevenção que o Projeto SIDA/AIDS vem desenvolvendo para essa população ${ }^{4}$.

A prevalência de cárie na dentição decídua foi maior nas crianças mais velhas e, nestas, nenhum paciente estava livre de cárie, quando comparada com a dos pacientes mais jovens, cujo percentual de crianças sem cárie foi de 46,8\%. Isto, provavelmente, ocorreu porque crianças mais velhas tendem a apresentar maior freqüência de cárie nos dentes decíduos, exatamente porque são estes os dentes há mais tempo na boca, estando há mais tempo expostos a todos os fatores de risco à cárie.

Estes achados corroboram com os de MADIGAN et al. ${ }^{12}$ (1996) que, ao trabalharem com pacientes infectados pelo HIV, observaram que, comparando com as crianças entre 3-6 anos de idade, aqueles com mais de 6 anos apresentavam maior prevalência de cárie tanto na dentição permanente $(1,0 \times 0)$ como, principalmente, na dentição decídua $(5,7 \mathrm{x}$ $3,2)$. O percentual de crianças livres de cárie encontrado por eles foi de $46,2 \%$ para as mais jovens e 6,7\% para as mais velhas. SQUASSI et al. ${ }^{15}$ (1997) também encontraram valores de ceo maiores para as crianças infectadas pelo HIV, com mais de 5 anos de idade e maior percentual de crianças livres de cárie para as mais jovens. Ainda no estudo de MADIGAN et al. ${ }^{12}$ (1996) os autores observaram que as crianças infectadas pelo HIV tinham niveis de estreptococos do grupo mutans e lactobacilos mais elevados que seu irmãos não infectados, e que, apesar desses dois grupos terem freqüência de ingestão de açúcar similar, as crianças infectadas pelo HIV eram mais susceptiveis aos efeitos da exposição freqüente aos carboidratos que as outras.

A higiene bucal deficiente e a diminuição do fluxo salivar também são fatores responsáveis pelos altos índices de cárie em crianças infectadas pelo HIV. O fato de muitos desses pacientes serem negligenciados por seus responsáveis pode contribuir para que a presença de grande quantidade de placa seja encontrada em cerca de $90 \%$ deles, como relata SMITH et al. ${ }^{14}$ (1994). Quanto ao fluxo salivar, este foi relacionado à prevalência de cárie em crianças infectadas pelo HIV num estudo de RIBEIRO et al. ${ }^{13}$ (1998), sendo a correlação entre eles negativa, ou seja, à medida que o fluxo diminuía, a freqüência de cárie aumentava. O uso de determinados medicamentos, como o ddI (didanosina) e a presença de hipertrofia de parótidas podem causar a diminuição da produção de saliva pela criança infectada.

O trabalho de VALDEZ et al. ${ }^{20}$ (1994) foi um dos primeiros a relacionar a prevalência de cárie com a deficiência imune do paciente infectado pelo HIV. Sabe-se que essas crianças estão muito expostas a fatores de risco à cárie, como consumo freqüente de carboidratos e higiene oral deficiente, mas estudos relacionando diretamente a imunossupressão pelo HIV (como por exemplo contagem e atividade de imunoglobulinas salivares dessas crianças) com a prevalência de cárie seriam de grande valia para a observação dessas variáveis.

Os resultados deste estudo mostram que a prevalência de cárie tendeu a ser maior naquelas crianças em estado mais avançado da doença. Quando avaliada a dentição decídua nas crianças mais jovens, observa-se que as médias de ceo entre as imunodeprimidas gravemente e entre as que apresentavam sintomas moderados ou graves apresentaram valores maiores, embora sem significância estatística. Nas crianças de maior idade, aquelas com imunossupressão grave também tenderam a apresentar mais cárie. Isto pode ser devido ao fato de que crianças mais doentes vão fazer uso mais freqüente de medicamentos e estes contêm teores elevados de açúcares. Além disso, estas crianças podem ser submetidas à terapia hipernutritiva, o que parece coincidir com o declinio das defesas contra a cárie ${ }^{12}$. Em estágios mais avançados da doença, a higiene oral também deve ficar prejudicada pela dificuldade de sua realização, devido à presença de lesões bucais.

Estes achados corroboram estudos de CASTRO et al. ${ }^{1}$ (1997) que observaram um declinio de CD4 à medida que o índice ceo aumentava e de VIEIRA et $a .^{21}$ (1998) no qual crianças com relação T4/T8 maior que 0,5 tinham menos cárie que aquelas com T4/T8 menor que 0,5. Em contrapartida, SQUASSI et al. ${ }^{15}$ (1997) não encontraram diferença 
CASTRO, G. F.; SOUZA, I. P. R. de; OLIVEIRA, R. H. S. e; PORTELA, M. B.; ESTEVES, C. Prevalência de cárie e sua correlação com a classificação clínica e imunológica em crianças infectadas pelo HIV. Pesqui Odontol Bras, v. 15, n. 2, p. 91-97, abr./jun. 2001.

entre a prevalência de cárie e o estágio da doença em criança infectada pelo HIV.

Como o uso de terapia anti-retroviral é um dos fatores de risco que parece estar altamente associado à prevalência de cárie nesta população ${ }^{6,8,9}$, esta correlação foi avaliada neste estudo. Para crianças mais jovens, embora não tenha havido diferença estatisticamente significante, a prevalência de cárie na dentição decídua foi duas vezes maior naquelas que faziam uso de alguma droga, sendo a média de idade similar entre os grupos. Nas crianças mais velhas, o mesmo foi verificado na dentição permanente. Parece que a terapia medicamentosa é, realmente, um dos primeiros fatores responsáveis pelo fato de a cárie dentária ser tão elevada nesta população e isto pode ser observado a partir do momento em que os dentes decíduos apresentam uma relação entre prevalência de cárie e uso de medicamentos anti-retrovirais mais evidenciada. Além disso, crianças mais jovens e, conseqüentemente, os dentes mais jovens, estão em maior risco, pois os medicamentos açucarados são aqueles apresentados sob a forma de xarope. Quando as crianças ficam mais velhas, estes são substituídos por cápsulas ou comprimidos.

Estudos mais específicos em relação à terapia medicamentosa em pacientes infectados pelo HIV e prevalência de cárie devem ser realizados, assim como a questão da imunossupressão dessas crianças deve ser avaliada. Importante ressaltar que, para analisar a relação cárie versus doença ou uso de medicamentos, há de se conduzir investigações de análise multivariada. Estudos dessa natureza certamente contribuirão para um tratamento mais eficaz desses pacientes, se considerado o problema cárie.

Os resultados aqui encontrados revelam que a equipe médica, incluindo o cirurgião-dentista que trata dessas crianças, também deve estar preparada para instruir os responsáveis das mesmas, quanto aos cuidados de higiene que eles devem ter em relação aos pacientes, quando do uso de medicamentos que contêm sacarose.

\section{CONCLUSÃO}

Apesar de não terem sido encontrados valores com diferenças estatisticamente significantes, houve uma tendência de a prevalência de cárie na dentição decídua de crianças de até cinco anos de idade ser maior naquelas mais comprometidas clínica e imunologicamente. Nas crianças com mais de cinco anos, a prevalência de cárie apresentou valores maiores naquelas com classificação clínica e imunológica mais avançada apenas na dentição permanente, ainda que sem significância estatística.

\footnotetext{
CASTRO, G. F.; SOUZA, I. P. R. de; OLIVEIRA, R. H. S. e; PORTELA, M. B.; ESTEVES, C. Prevalence of caries and its correlation with clinical and immunological classification in HIV-infected children. Pesqui Odontol Bras, v. 15, n. 2, p. 91-97, abr./jun. 2001.
}

\begin{abstract}
This research aims to determine the relationship between the prevalence of caries and clinical and immunological classification in HIV-infected children. Ninety-two outpatients (42 male and 50 female subjects) with definitive diagnosis of HIV infection took part in this research. The patients were examined in order to determine the prevalence of caries (dmf and DMFT indexes), and medical data were collected from their medical records. The mean age of the subjects was 5.77 years. Although no statistical differences were found, young patients (up to 5 years old) had more caries when they were more clinically and immunologically compromised. The same fact was observed regarding older children.
\end{abstract}

UNITERMS: HIV infections; Dental caries; Child.

\section{REFERÊNCIAS BIBLIOGRÁFICAS}

1. CASTRO, G. F.; SOUZA, I. P. R.; NEVES, A. et al. Relationship between caries experience and immunossupression degree in HIV+ children. J Dent Res, v. 76, n. 5, p. 950, May 1997. [Resumo n. 2]

2. CASTRO, G. F. B. A.; SOUZA, I. P. R.; VIANNA, R. et al. Identification of caries prevalence and its relationship with caries risk in HIV+ children with no evidence of immunodeficiency. J Dent Res, v. 75, n. 5, p. 1107, May 1996. [Resumo n. 231]

3. CDC - Centers for Disease Control and Prevention. 1994
Revised classification system for human immunodeficiency virus infection in children with less than 13 years of age. MMWR, v. 43, n. RR-12, p. 1-19, Sept. 1994.

4. ESTEVES, C. C.; CASTRO, G. F.; FERnANDES, A. C. et al. Incremento de cárie após dois programas de prevenção em crianças HIV+. In: REUNIÃO ANUAL DA SBPqO, 15, 1998, Águas de São Pedro. Anais. 1998. [Resumo A 68]

5. FRENCKEN, J. et al. Atraumatic restorative treatment (ART): rationale, technique and development. J Public Health Dent, v. 56, n. 3, p. 135-140, 1996.

6. GEHRKE, F. S.; JOHNSEN, D. S. Bottle caries associated 
CASTRO, G. F.; SOUZA, I. P. R. de; OLIVEIRA, R. H. S. e; PORTELA, M. B.; ESTEVES, C. Prevalência de cárie e sua correlação com a classificação clínica e imunológica em crianças infectadas pelo HIV. Pesqui Odontol Bras, v. 15, n. 2, p. 91-97, abr./jun. 2001.

with anti-HIV therapy. Pediatr Dent, v. 13, n. 1, p. 73, Jan./Feb. 1991.

7.GREENE,J.C.;VERMILLION,J.R.Thesimplifiedoral hygiene index. J Am Dent Assoc, v. 68, n. 1, p. 7-13, Jan. 1964.

8. GREENSPAN, J. S.; GREENSPAN, D. Oral lesions associated with HIV infection. In: AIDS and other manifestations of HIV infection. 2. ed. New York: Gary P. Worm-

9. ser, 1992. Cap. 32, p. 489-498.

AIDS. In: BRODER, S.; MERIGAN, T. C.; BOLOGNESI, D. Textbook of AIDS medicine, Baltimore : Willians \& Wilkins, 1994. Cap. 33, p. 525-539.

10. HOWELL, R. B.; JANDINSKI, J.; PALUMBO, P. et al. Dental caries in HIV-infected children. Pediatr Dent, v. 14, n. 6, p. 370-371, Nov./Dec. 1992.

11. LIMA, K. T.; ALMEIDA, C. S.; SENA, E. L. Edulcorantes e $\mathrm{pH}$ endógeno de medicamentos pediátricos. In: REUNIÃO ANUAL DA SBPqO, 16, 1999, Águas de São Pedro. Anais. 1999. [Resumo B 110]

12. MADIGAN, A.; MURRAY, P. A.; HOUPT, M. et al. Caries experience and cariogenic markers in HIV-positive children and their siblings. Pediatr Dent, v. 18, n. 2, p. 129-136, Mar./Apr. 1996.

13. RIBEIRO, A. A.; BUNDZMAN, E. R.; CASTRO, G. F. et al. Relation between salivary flow, medicines and caries in HIV+ children. J Dent Res, v. 77, p. 841, July 1998. [Resumo n. 1.676]

14. SMITH, L. A.; NORDSTROM, N. K.; WHITACRE, H. L. et al.
HIV-seropositive children: oral manifestations and educational guidelines for caregivers. J Dent Res, v. 73, p. 334, 1994. Special issue.

15. SQUASSI, A.; ALESSANDRELLO, H.; BORDONI, N. et al. Dental status in children with human immunodeficiency virus infection. J Dent Res, v. 76, n. 5, p. 919, May 1997. [Resumo n. 12]

16. SOUZA, I. P. R.; PRIMO, L. G.; CASTRO, G. F. B. A. Evaluation of caries risk factors in high and low risk HIV+ children. J Dent Res, v. 75, n. 5, p. 1107, May 1996. [Resumo n. 238]

17. SOUZA, I. P. R.; TEles, G. S.; CASTRO, G. F. et al. Prevalência de cárie em crianças infectadas pelo HIV. Rev Bras Odontol, v. 53, n. 1, p. 49-51, jan./fev. 1996.

18. TOFSKY, N.; CATALANOTTO, F.; SCHOEN, D. et al. Dental caries in HIV+ children: 1-year findings. J Dent Res, v. 75, p. 405, 1996. [Resumo n. 3.097]

19. TOFSKY, N.; SCHOEN, D.; JANDINSKI, J. et al. Dental caries in children with AIDS. J Dent Res, v. 74, p. 191, 1995. [Resumo n. 1.438]

20. VALDEZ, I. M.; PIZZO, P. A.; ATKINSON, J. C. Oral health of pediatric AIDS patients: a hospital-based study. J Dent Child, v. 61, n. 2, p. 114-18, Mar./Apr. 1994.

21. VIEIRA, A. R.; SOUZA, I. P. R. S.; MODESTO, A. et al. Gingival status of HIV+ children and the correlation with caries incidence and immunologic profile. Pediatr Dent, v. 20, n. 3, p. 169-172, 1998.

22. WORLD HEALTH ORGANIZATION (WHO). Oral health surveys - basic methods, Geneva, 3. ed., 1987. 56 p.

Recebido para publicação em 16/03/00

Enviado para reformulação em 07/02/01

Aceito para publicação em 02/03/01 